\title{
Robust organic cages prepared using hydrazone condensation display sulfate/hydrogenphosphate selectivity in water
}

\author{
Émer M. Foyle, ${ }^{a}$ Thomas G. Mason, ${ }^{b}$ Michelle L. Coote, ${ }^{a}$ Ekaterina I. Izgorodina, ${ }^{\text {b* }}$ and Nicholas G. \\ White ${ }^{\text {a* }}$ \\ ${ }^{a}$ Research School of Chemistry, The Australian National Univeristy, Canberra, ACT, Australia \\ ${ }^{b}$ School of Chemistry, Monash University, Clayton, VIC, Australia \\ * katya.pas@monash.edu, https://mccg.erc.monash.edu; nicholas.white@anu.edu.au, www.nwhitegroup.com
}

\begin{abstract}
Two robust hexacationic cages incorporating either urea or isophthalamide motifs were synthesized via a short and high-yielding synthetic pathway using hydrazone condensation reactions in water for the cage forming step. Stability testing revealed that the cages are stable to a range of stimuli in water and in organic solvents. The urea containing cage can bind anions in pure water, and displays strong and selective binding of $\mathrm{SO}_{4}{ }^{2-}$ over $\mathrm{HPO}_{4}{ }^{2-}$. The isophthalamide containing cage binds $\mathrm{SO}_{4}{ }^{2-}$ only weakly in 1:1 $\mathrm{D}_{2} \mathrm{O}: \mathrm{d}_{6}$-DMSO but displays strong and cooperative binding of two $\mathrm{HPO}_{4}{ }^{2-}$ anions. Combined quantum mechanical/annealed molecular dynamics simulations suggest that the remarkable differences in anion selectivity are largely a result of the differing flexibilities of the two cages.
\end{abstract}

\section{INTRODUCTION}

One of the challenges for synthetic anion receptors to go from academic laboratories to real world applications is that the majority of receptors are unable to function in aqueous solutions. ${ }^{1,} 2$ Binding of anions in water is a challenge due to the intrinsic nature of both water and anions. Water is a highly competitive solvent that can hydrogen bond to anions, therefore any receptor must out-compete this interaction in order to bind the guest. Anions themselves are harder to bind then their equivalent cations due to their larger size, ${ }^{3}$ which leads to weaker electrostatic interactions with hosts, while also having high solvation energies. While there have been some notable examples of receptors that can function in water, the majority of receptors are unable to do so.4-6 In addition to difficulties binding in water, selectivity is a major challenge. Systems have been reported that display a selectivity preference for more highly charged anions over those with lower charge,7,8 or based on anion hydrophobicity, ${ }^{9-11}$ but systems that show significant selectivity between similar anions such as $\mathrm{SO}_{4}{ }^{2-}$ and $\mathrm{HPO}_{4}{ }^{2-}$ are extremely rare. ${ }^{12-14}$

Dynamic covalent chemistry has been used to synthesize a range of organic supramolecular architectures: the reversible nature of the bond formation reactions means an "error checking" process can occur ${ }^{15}$ leading to the formation of complex structures in high yields that would be very challenging to synthesize otherwise. ${ }^{16}$ The imine formation reaction is the most popular choice leading to a range of architectures including cages, 17-23 interlocked molecules $24-30$ and covalent frameworks. ${ }^{31,} 32$ While imines have proved useful, they have a major drawback as they are typically not stable in the presence of water and this limits their applications in biological or real world settings. There are notable exceptions where imine based structures have been synthesized in water, but these structures tend to be unstable or hard to isolate. ${ }^{33-36}$ On the other hand, hydrazones are stable in water and can form easily and reversibly in aqueous solutions, usually in the presence of an acid catalyst. ${ }^{37}$ The hydrazone reaction has been used to synthesis interlocked structures, ${ }^{38-40}$ macrocycles ${ }^{41-43}$ and knots. ${ }^{44}$ Currently only a small number of cages have been reported. ${ }^{45-48}$ The first of these, $\mathrm{I}^{6+}$, reported by $\mathrm{Yang}$ and $\mathrm{Li}$, was synthesized on an NMR scale and could bind large aromatic guests in water but is not stable in the solution phase over extended periods. ${ }^{45}$ Recently, $\mathrm{Li}$ and Sessler reported $\mathbf{2}^{6+}$, which binds two anions simultaneously in acetonitrile, and forces them within van der Waals radii of each other. ${ }^{46}$ We reasoned that hydrazone condensation reactions could be used to assemble similar polycationic cages that would be capable of selective anion recognition in water due to their highly charged and organized three dimensional cavities. In this work, we report two new cages, and demonstrate that they are highly robust, and capable of selectively binding either $\mathrm{SO}_{4}{ }^{2-}$ or $\mathrm{HPO}_{4}{ }^{2-}$ anions in water or water/DMSO mixtures.
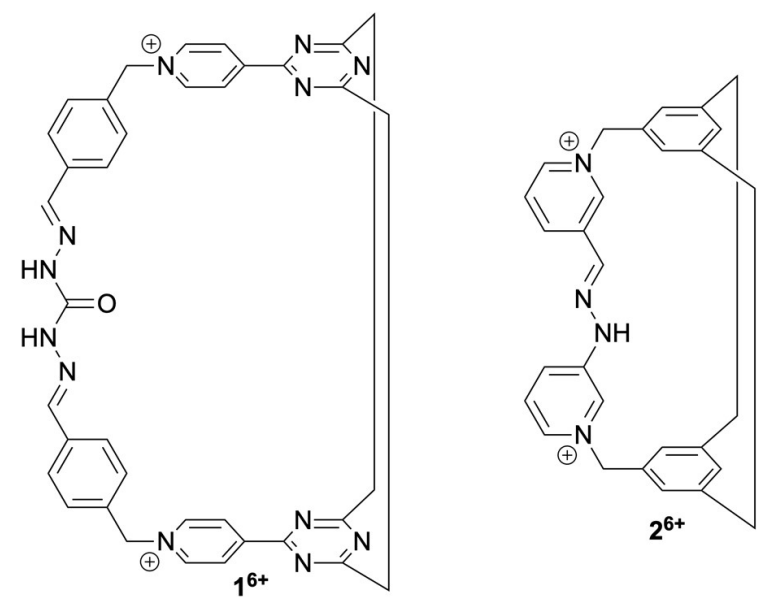

Figure I. Previously-reported hydrazone cages $\mathbf{1}^{6+}$ and $2^{6+}$ (only one "arm" of each three-fold symmetric cage molecule is shown for clarity). 


\section{RESULTS AND DISCUSSION}

Synthesis and $X$-ray crystal structures of cages The new hexacationic cages $\mathbf{3 6}^{6+}$ and $\mathbf{4 6}^{6+}$ were prepared via short synthetic sequences: tripodal aldehyde $\mathbf{5}$ was synthesized in one step from commercially available 1,3,5-tris(bromomethyl)2,4,6-triethylbenzene (6) and 4-pyridinecarboxaldehyde in $88 \%$ yield (Figure 2). The known hydrazides $\mathbf{7}$ and $\mathbf{8}$ were readily synthesized from isophthalic acid or dimethylcarbonate using literature procedures. ${ }^{44,49,50}$ To test if the synthesis of these cages through hydrazone formation was viable, NMR scale reactions were initially conducted at $80^{\circ} \mathrm{C}$ in $\mathrm{D}_{2} \mathrm{O}$ with TFA as an acid catalyst. When the urea hydrazide 8 was used, the $\mathrm{IH}$ NMR spectrum showed the reaction had gone to completion after 15 hours with no further changes in the spectrum after this (Figure S2I). When isophthaloyl hydrazide 7 was used, NMR spectroscopy showed that the cage formation reaction went to completion after 48 hours but further heating of the solution led to degradation of the cage (Figure S20). The reactions were then scaled up (100-200 mg scale) so that the desired cages could be isolated from the reaction solution by precipitation as the $\mathrm{PF}_{6}{ }^{-}$salts. This gave cages $\mathbf{3} \cdot\left(\mathbf{P F}_{6}\right)_{6}$ and $4 \cdot\left(P_{6}\right)_{6}$ in yields of 68 and $74 \%$, respectively.

The water-soluble cages, $\mathbf{3} \cdot \mathbf{C l}_{6}, \mathbf{3} \cdot\left(\mathbf{N O}_{3}\right)_{6}, 4 \cdot \mathbf{C l}_{6}$ and 4. $\left(\mathrm{NO}_{3}\right)_{6}$ were isolated by precipitation by adding TBA $\cdot \mathrm{Cl}$ or $\mathrm{TBA} \cdot \mathrm{NO}_{3}$ in acetonitrile to acetonitrile solutions of $\mathbf{3} \cdot\left(\mathbf{P F}_{6}\right)_{6}$ or $\mathbf{4}^{-}\left(\mathbf{P F}_{6}\right)_{6}$. The cages were characterized by ${ }^{1} \mathrm{H},{ }^{13} \mathrm{C}$ and
DOSY NMR spectroscopy, as well as high resolution mass spectrometry. Additionally, both cages were characterized by X-ray crystallography, with crystal structures obtained for 3. $\left(\mathbf{P F}_{6}\right)_{5} \cdot \mathbf{B r}, \mathbf{4} \cdot\left(\mathbf{N O}_{3}\right)_{6}$ and $\mathbf{4} \cdot\left(\mathrm{HPO}_{4}\right)_{3}$ (Figure 2). Crystals of 3. $\left(\mathbf{P F}_{6}\right)_{5} \cdot \mathbf{B r}$ were obtained when crystallizing what was believed to be $3 \cdot\left(\mathbf{P F}_{6}\right)_{6}$ implying that traces of $\mathrm{Br}$ - remained after anion exchange. Quantitative ${ }^{19} \mathrm{~F}$ NMR spectroscopy against an internal standard indicated 6.0 equivalents of $\mathrm{PF}_{6}^{-}$per cage, suggesting that only minute traces of $\mathrm{Br}^{-}$are present. ${ }^{51}$ Interestingly, two of the three isophthalamide motifs in $\mathbf{3} \cdot \mathbf{B r} \cdot\left(\mathbf{P F}_{6}\right)_{5}$ adopt a syn-anti conformation with one $\mathrm{N}-\mathrm{H}$ group on each of these pointing into the cage cavity and another pointing outwards. The third isophthalamide adopts a syn-syn conformation with both $\mathrm{N}-\mathrm{H}$ groups hydrogen bonding to a bromide anion located within the cage cavity. In the structure of $\mathbf{4} \cdot\left(\mathbf{N O}_{3}\right)_{6}$, all urea groups adopt a syn-anti conformation. Crystals of $4 \cdot\left(\mathbf{H P O}_{4}\right)_{3}$ were obtained from a solution of $4 \cdot\left(\mathbf{N O}_{3}\right)_{6}$ and ten equivalents of $\mathrm{TBA}_{2} \cdot \mathrm{HPO}_{4}$, and in this structure all urea $\mathrm{N}-$ $\mathrm{H}$ groups point out of the cage cavity, with the anions being coordinated exterior to the cage. It is notable that there is considerable conformation flexibility associated with the cages, and with the geometries of the hydrazide groups.

Stability of hydrazone cages Until now the stability of hydrazone cages in the solution phase has not been fully investigated so we examined the stability of the two cages (these results are
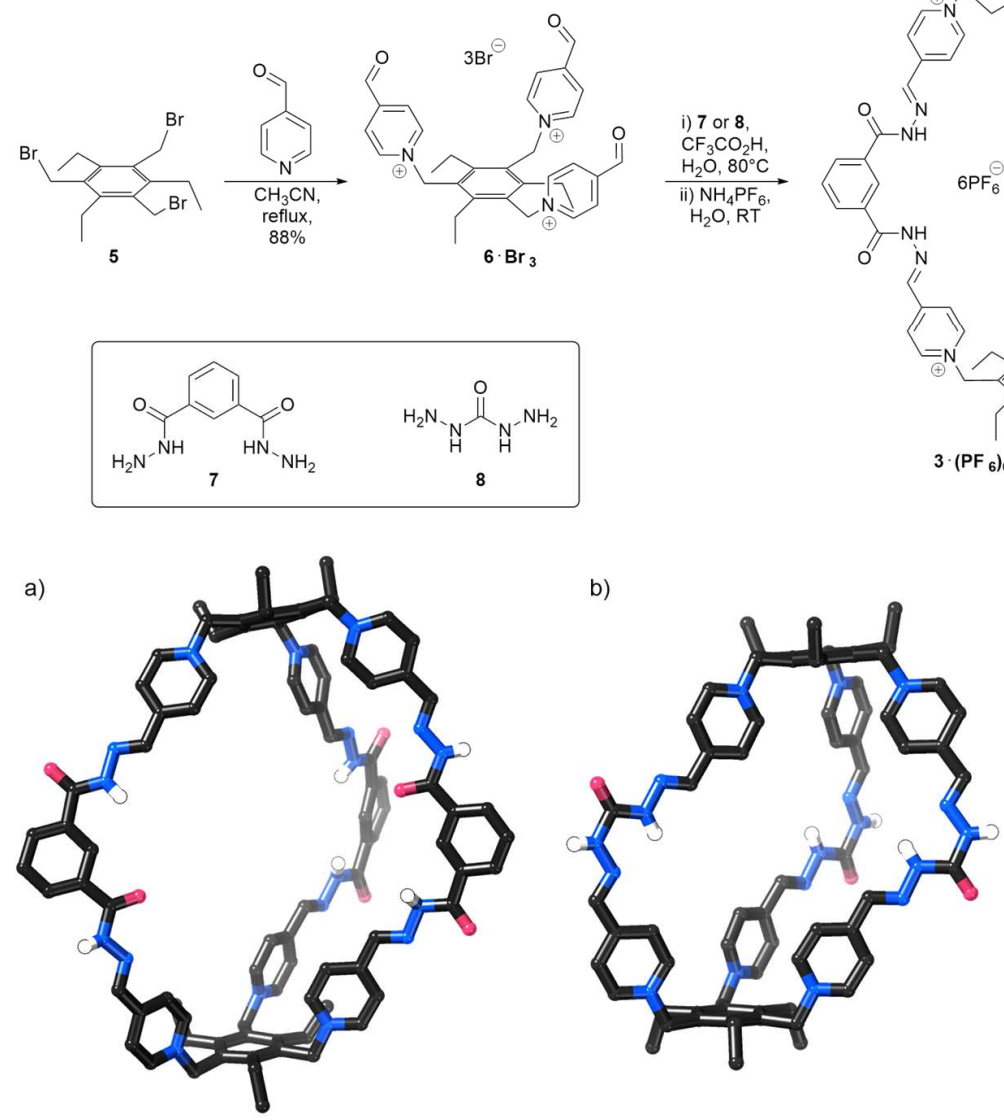
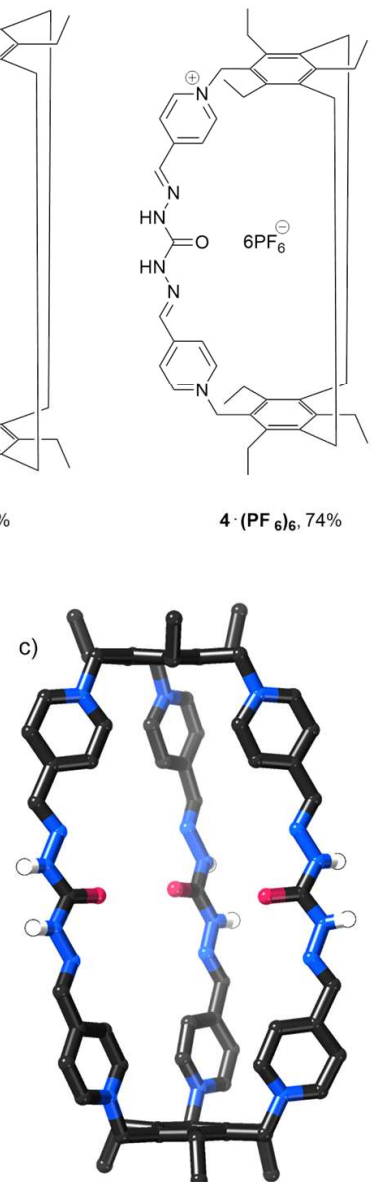

Figure 2. Synthesis of new cages $3\left(\mathbf{P F}_{6}\right)_{6}$ and $4\left(\mathbf{P F}_{6}\right)_{6}$ (only one "arm" of each cage molecule is shown for clarity) and $\mathrm{X}_{\text {-ray }}$ crystal structures of a) $3 \cdot \mathbf{B r} \cdot\left(\mathbf{P F}_{6}\right)_{5}$, b) $4 \cdot\left(\mathrm{NO}_{3}\right)_{6}$ and c) $4 \cdot\left(\mathrm{HPO}_{4}\right)_{3}$ (anions, solvent molecules, and most hydrogen atoms omitted for clarity). 
summarised in Table SI). We investigated stability to both low and high temperatures as well as to acid and base, and conducted both sets of tests in both water and organic solvent. All stability tests were carried out using 'H NMR spectroscopy at a concentration of $5.0 \mathrm{mM}$ in either $\mathrm{D}_{2} \mathrm{O}$ for $\mathbf{3} \cdot \mathrm{Cl}_{6}$ and $\mathbf{4} \cdot \mathrm{Cl}_{6}$ or $\mathrm{d}_{6}$-DMSO for 3.(PF $)_{6}$ or $\mathbf{4} \cdot\left(\mathbf{P F}_{6}\right)_{6}$. None of the cages showed changes in their 'H NMR spectra at room temperature after 42 days in either $D_{2} O$ or $d_{6}$-DMSO. The same samples were then subjected to heating for 48 hours at $80^{\circ} \mathrm{C}$. No evidence of decomposition was observed for either the $\mathrm{Cl}^{-}$or $\mathrm{PF}_{6}{ }^{-}$salt of $3^{6+}$, while $\mathbf{4} \cdot \mathrm{Cl}_{6}$ remained stable after heating in $\mathrm{D}_{2} \mathrm{O}$ but $\mathbf{4} \cdot\left(\mathbf{P F}_{6}\right)_{6}$ showed some evidence of decomposition after heating in $\mathrm{d}_{6}$ DMSO ( 20\% after 48 hours heating, see Figure S28). Li and co-workers reported that $\mathbf{1}^{6+}$ decomposed completely upon standing in cold water, ${ }^{45}$ therefore we tested the stability of our cages at low temperatures (approx. $4{ }^{\circ} \mathrm{C}$ ). Solutions of $\mathbf{3} \cdot\left(\mathbf{P F}_{6}\right)_{6}$ and $4 \cdot\left(P_{6}\right)_{6}$ in $\mathrm{CD}_{3} \mathrm{CN}$ ( $\mathrm{d}_{6}$-DMSO could not be used as it freezes at these temperatures) and solutions of $3 \cdot \mathbf{C l}_{6}$ and $\mathbf{4} \cdot \mathbf{C l}_{\mathbf{6}}$ in $\mathrm{D}_{2} \mathrm{O}$ showed no change in their NMR spectra after 42 days, indicating good stability at low temperatures.

The stability of $\mathbf{3} \cdot \mathrm{Cl}_{6}$ and $\mathbf{4} \cdot \mathrm{Cl}_{\mathbf{6}}$ in both aqueous acidic (DCl) and basic $(\mathrm{NaOH})$ conditions was also investigated. Due to solubility issues the $\mathrm{pH}$ for stability testing could not be lower than 2 or higher than 10 as this resulted in precipitation. Isophthalamide cage $3 \mathbf{C l}_{6}$ showed no change after 42 days at $\mathrm{pH} 10$ while at $\mathrm{pH} 2$ some decomposition ( 30\%, see Figure S34) was observed after 42 days. This is not surprising as it was seen when studying cage formation (which used an acid catalyst) that if the reaction was left on longer than $\mathbf{4 8}$ hours other peaks started appearing in the in the reaction mixture. The urea cage $4 \mathrm{Cl}_{6}$ is stable at $\mathrm{pH} 2$ and $\mathrm{pH} 10$ over 42 days.

Anion binding properties of $3^{6+}$ and $4^{6+}$. As the cages have a high positive charge and are soluble in water as their chloride or nitrate salts, we reasoned that they may be able to bind anions through a combination of hydrogen bonds and electrostatic attraction. Anion binding was investigated using 'H NMR titration experiments in conjunction with combined polarisable molecular dynamics simulations and density functional theory (DFT) calculations. Briefly, simulated annealing of each cage in a I:I DMSO:water mixture was performed to generate realistic initial configurations, with lower energy configurations extracted from subsequent 10 ns NVT simulations. In order to increase sampling of possible interactions between the cage and added anions, three anions (either $\mathrm{HPO}_{4}{ }^{2-}$ or $\mathrm{SO}_{4}{ }^{2-}$ ) were included with both cages, $3^{6+}$ and $4^{6+}$. These calculations maintain the neutrality of the cage charge when three anions are added, which is important to achieve meaningful results. 52 These structures were further interrogated using M06-2X calculations to compute interaction energies between the cage and anions (see Supporting Information for details).

Initially, the binding of anions (added as their sodium salts) to the urea cage $4\left(\mathbf{N O}_{3}\right)_{6}$ was investigated in $\mathrm{D}_{2} \mathrm{O}$. These experiments revealed that the cage showed no response to monovalent $\mathrm{OAc}^{-}$or $\mathrm{H}_{2} \mathrm{PO}_{4}{ }^{-}$. Addition of divalent $\mathrm{HPO}_{4}{ }^{2-}$ caused upfield shifts in the pyridinium ring proton resonances, ${ }^{53}$ and analysis of the titration data using Bindfit ${ }^{54}$ indicated a $\mathrm{I}: \mathrm{I}$ binding stoichiometry with an association constant of $280 \pm 30 \mathrm{M}^{-1} .55$ Addition of sulfate resulted in precipitation after approximately two equivalents of anion, but before this point the data were consistent with very strong $\left(>10^{4} \mathrm{M}^{-1}\right)$ binding of sulfate. Due to the precipitation observed in pure $\mathrm{D}_{2} \mathrm{O}$, we repeated these titrations in $1: 1 D_{2} \mathrm{O}: \mathrm{d}_{6}-\mathrm{DMSO}$, which were again consistent with very strong sulfate binding and a high $\mathrm{SO}_{4}{ }^{2-}: \mathrm{HPO}_{4}{ }^{2-}$ selectivity (Table I).
Table I. Association constants ${ }^{a}\left(\mathrm{M}^{-1}\right)$ for binding of anions to $4 \cdot\left(\mathrm{NO}_{3}\right)_{6}$.

\begin{tabular}{ccc}
\hline & $\mathrm{HPO}_{4}{ }^{2-}$ & $\mathrm{SO}_{4}{ }^{2-}$ \\
\hline $\mathrm{D}_{2} \mathrm{O}$ & $2.8(3) \times 10^{2}$ & $>10^{4 b}$ \\
$\mathrm{I}: \mathrm{I}_{2} \mathrm{O}: \mathrm{d}_{6}-\mathrm{DMSO}$ & $6.3(8) \times 10^{2 c}$ & $>10^{4}$
\end{tabular}

${ }^{a}$ Determined using Bindfit, ${ }^{54}$ anions added as $\mathrm{Na}^{+}$salts in $\mathrm{D}_{2} \mathrm{O}$ titrations and as $\mathrm{TBA}^{+}$salts in $1: 1 \mathrm{D}_{2} \mathrm{O}: \mathrm{d}_{6}$-DMSO titrations. The asymptotic error ${ }^{56}$ at the $95 \%$ confidence interval is given in parentheses. ${ }^{b}$ Precipitation after 2.0 equivalents of anion. ${ }^{c}$ Precipitation after 3.0 equivalents of anion.

Interestingly, while we could obtain crystals of $\mathbf{4}\left(\mathrm{HPO}_{4}\right)_{3}$ from a solution containing $4\left(\mathbf{N O}_{3}\right)_{6}$ and ten equivalents of $\mathrm{Na}_{2} \mathrm{HPO}_{4}$, in these crystals the anions bind outside of the cage's cavity (Figure $2 \mathrm{c}$ and S63), consistent with the relatively weak binding of this anion. This is also observed in the simulations: no entry of $\mathrm{HPO}_{4}{ }^{2-}$ to the cage's cavity is observed with these anions remaining persistently far (> $5 \AA$ ) from the cage during the simulations (Figure $3 \mathrm{a}$ ). The cage adopts a relatively long and thin $(\sim 18 \times 1 \mid \AA)$ configuration similar to that seen in the crystal structure of $\mathbf{4} \cdot\left(\mathrm{HPO}_{4}\right)_{3}$ (Figure $2 \mathrm{c}$ ) and it appears that there is insufficient space to accommodate the $\mathrm{HPO}_{4}{ }^{2-}$ anion, presumably due to the extra size and electropositive region provided by the anion's hydrogen atom.

a)

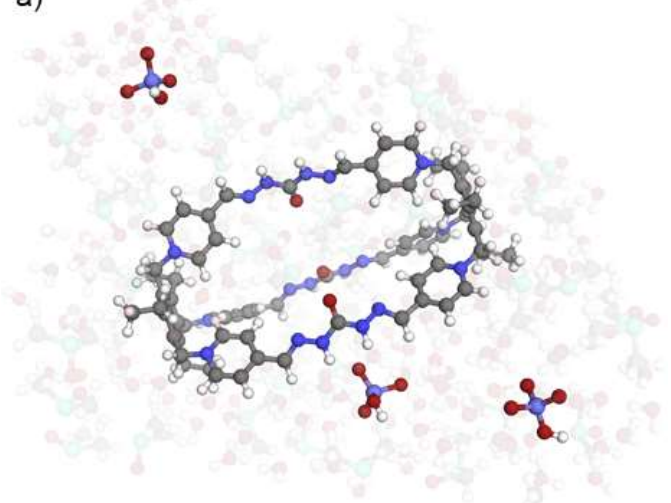

b)

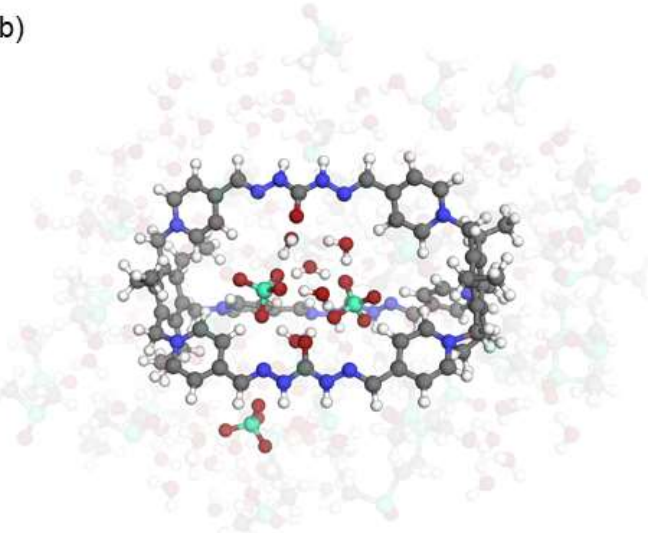

Figure 3. Simulated annealing structures of $4^{6+}$ in the presence of three ions showing that a) in the case $\mathrm{HPO}_{4}{ }^{2-}$ one anion is bound to the outside of the cage and the other two anions remain unbound and $b$ ) in the case of $\mathrm{SO}_{4}{ }^{2-}$ all three anions remain strongly bound on the outside. Solvent molecules are shown in the background. Water molecules forming a hydrogenbonded network between $\mathrm{SO}_{4}{ }^{2-}$ anions are explicitly shown.

In contrast, the $\mathrm{SO}_{4}{ }^{2-}$ simulations show that all three anions stay close to the cage and can at times enter the cage, and we suggest that this explains the surprisingly high selectivity exhibited by $4^{6+}$. In the lowest energy conformation, two anions perch slightly outside of the cage cavity forming a hydrogen bonded water network connecting two anions (Figure $3 b$ ). In the NMR 
studies, the pyridinium $\mathrm{C}-\mathrm{H}$ proton resonances move in different directions upon the addition of $\mathrm{HPO}_{4}{ }^{2-}$ (upfield) and $\mathrm{SO}_{4}{ }^{2-}$ (downfield), which is consistent with the different binding modes of these two anions observed in the simulations.

Interaction energy calculations further support these observations. In general, relatively moderate binding energies were obtained, consistent with the relatively weak nature of supramolecular anion recognition and the highly competitive solvent. On average, values of $-4.5 \mathrm{kcal} \mathrm{mol}^{-1}$ were obtained for $\mathrm{HPO}_{4}{ }^{2-}$ , whereas stronger binding of $-5.3 \mathrm{kcal} \mathrm{mol}^{-1}$ was observed for $\mathrm{SO}_{4}{ }^{2-}$, although we note that there will be considerable errors associated with these values. The interaction is as expected predominantly attractive electrostatic as further supported by electrostatic potential maps (Figures S68-S7I).

Attempts to probe the binding of anions to phenyl substituted cage $3\left(\mathbf{N O}_{3}\right)_{6}$ using NMR titration experiments in $\mathrm{D}_{2} \mathrm{O}$ were hampered by precipitation upon addition of $\mathrm{HPO}_{4}{ }^{2-}$ or $\mathrm{SO}_{4}{ }^{2-}$. Conducting the titrations in $\mathrm{D}_{2} \mathrm{O}$ containing $10 \%(\mathrm{v} / \mathrm{v})$ $\mathrm{d}_{6}$-DMSO allowed us to obtain binding data for $\mathrm{HPO}_{4}{ }^{2-}$, which indicated relatively strong binding of this guest - although there was evidence of more than one binding stoichiometry (see Supporting Information). Addition of $\mathrm{SO}_{4}{ }^{2-}$ resulted in precipitation so we were unable to calculate an association constant.

Given the difficulties resulting from precipitation in $\mathrm{D}_{2} \mathrm{O}$ and 9:I $\mathrm{D}_{2} \mathrm{O}: \mathrm{d}_{6}$-DMSO, we conducted further anion binding studies in $\mathrm{I}: \mathrm{I} \mathrm{D}_{2} \mathrm{O}: \mathrm{d}_{6}$-DMSO, which revealed modest $\mathrm{I}: \mathrm{I}$ binding of $\mathrm{SO}_{4}{ }^{2-}\left(K_{\mathrm{a}}: 430 \pm 20 \mathrm{M}^{-1}\right.$, Figure 4). When $\mathrm{HPO}_{4}{ }^{2-}$ is added to $3\left(\mathbf{N O}_{3}\right)_{6}$ in this highly competitive medium, initially very little peak movement is observed $(<0.01 \mathrm{ppm}$ shift in the imine peak after 1.0 equivalents of anion), but this is followed by much larger shifts on increasing anion concentration (Figure 4). This kind of binding isotherm is consistent with cooperative binding, and indeed the data are consistent with a $1: 2$ binding isotherm with $K_{1: 1}=\left\langle 1 M^{-1}\right.$ and $\left.K_{1: 2}>10^{4} M^{-1}\right)$. DOSY NMR showed no increase in the size of the species in solution upon addition of $\mathrm{HPO}_{4}{ }^{2-}$, suggesting cooperative binding within the cage cavity, rather than anion-linked assembly of cages into larger assemblies. ${ }^{57}$ We note that this is very different binding behaviour to that observed for urea cage $\mathbf{4}^{6+}$, which showed a strong preference for sulfate and unambiguous I:I binding stoichiometries for both anions.

Simulations of $\mathrm{HPO}_{4}{ }^{2-}$ and $\mathrm{SO}_{4}{ }^{2-}$ binding to $3^{6+}$ are again consistent with the observed binding selectivity. Two of the three $\mathrm{HPO}_{4}^{-}$anions tend to aggregate together and bind inside the cage (Figure 5). Interestingly, sulfate anions do appear to associate with each other to some extent, forming solvent bridged anion aggregates ${ }^{58}$ but these are located outside the cage cavity. While the $\mathrm{HPO}_{4}{ }^{2-}$ anions associate ${ }^{59}$ and bind together within the cage, this does not appear to be a classical antielectrostatic hydrogen bond as the anions are located further than $3.3 \AA$ (O...O distance) away from each other, 60 and instead solvent molecules seem to facilitate this anion clustering (see Figure 5a). a)

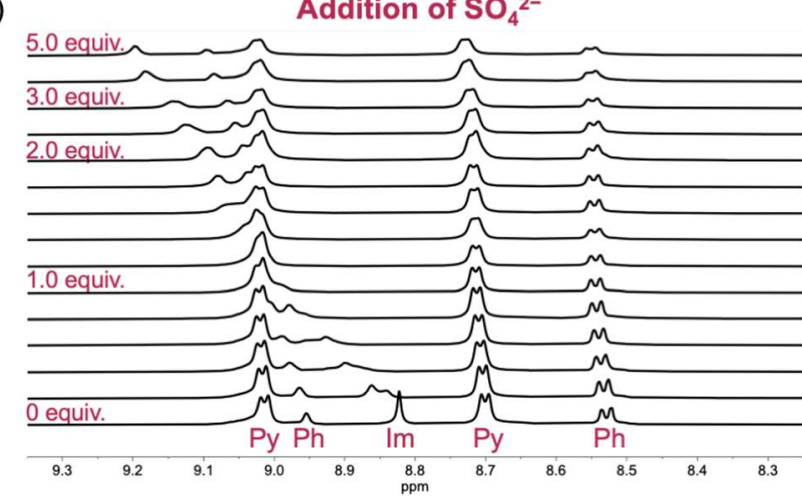

b)

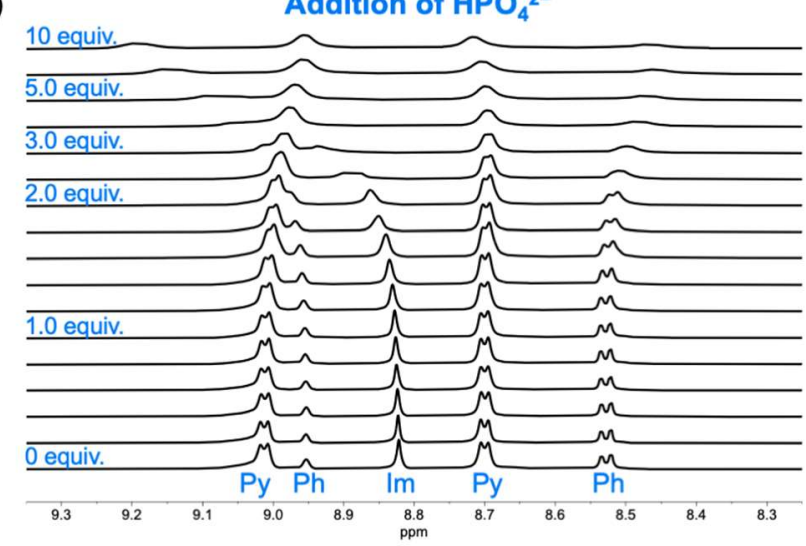

c)

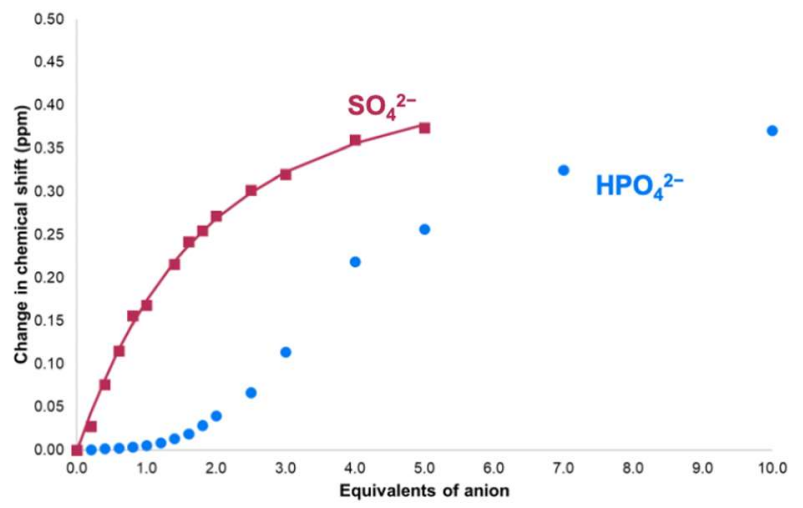

Figure 4. Binding of anions by $3 \cdot\left(\mathrm{NO}_{3}\right)_{6}$ in $\mathrm{I}: \mathrm{I}_{2} \mathrm{O}: \mathrm{d}_{6}-\mathrm{DMSO}$. a) Partial ${ }^{\prime} \mathrm{H}$ NMR spectra of $3 \cdot\left(\mathrm{NO}_{3}\right)_{6}$ on addition of $\mathrm{SO}_{4}{ }^{2-}(298 \mathrm{~K}, 600 \mathrm{MHz})$, b) partial 'H NMR spectra of $3 \cdot\left(\mathrm{NO}_{3}\right)_{6}$ on addition of $\left.\mathrm{HPO}_{4}{ }^{2-}(298 \mathrm{~K}, 600 \mathrm{MHz}), \mathrm{c}\right)$ movement of imine proton resonance upon addition of anions; square/circles represent datapoints, line represents I:I binding isotherm fitted using Bindfit. Due to the strong binding constant obtained for $\mathrm{HPO}_{4}{ }^{2-}$, it was not possible to fit the data quantitatively, but qualitatively the data are consistent with $K_{1: 1}<I M^{-1}, K_{1: 2}>10^{4} \mathrm{M}^{-1}$. Labelling for NMR spectra: $P y=$ pyridinium, $\mathrm{Ph}=$ phenyl (i.e. the isophthalamide ring), $\mathrm{Im}=$ imine.

Binding energy per anion results suggest stronger binding for $\mathrm{SO}_{4}{ }^{2-}\left(-4.5 \mathrm{kcal} \mathrm{mol}^{-1}\right)$ over $\mathrm{HPO}_{4}{ }^{2-}$ anion $\left(-3.7 \mathrm{kcal} \mathrm{mol}^{-1}\right)$, which is not consistent with the experimental data. The anion aggregation is rather strong between the two $\mathrm{HPO}_{4}{ }^{2-}$ anions, as evidenced by a single water molecule bridging these (Figure $5 \mathrm{a}$ ). Since water molecules were not explicitly included in the binding energy calculations, this aggregation is more likely to introduce a repulsive electrostatic component, thus resulting in artificially weakened binding for $\mathrm{HPO}_{4}{ }^{2-}$ over $\mathrm{SO}_{4}{ }^{2-}$. It has to be noted that the presented binding energies do not account for entropic effects due to computational infeasibility of calculating vibrational frequencies. It is expected that these entropic contributions will further favour the thermodynamic binding due to 
a positive change in the overall entropy, thus making the resulting binding energy stronger than currently reported.

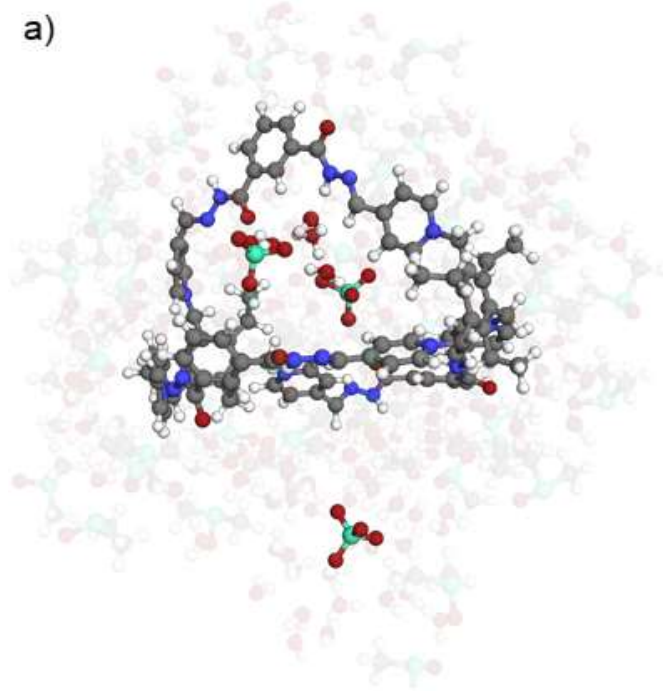

b)

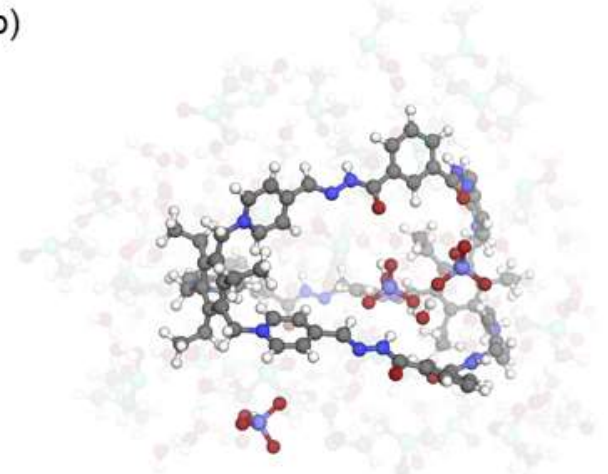

Figure 5. Simulated binding of a) three $\mathrm{HPO}_{4}{ }^{2-}$ anions and b) three $\mathrm{SO}_{4}{ }^{2-}$ anions to $3^{6+}$. Bridging water molecules between anions are explicitly shown.

\section{CONCLUSIONS}

Two hexacationic water soluble cages have been synthesized using hydrazone condensation reactions in high yields. Studies of the solution phase stability of both cages revealed surprisingly high stability to a range of conditions. The urea-based cage binds sulfate very strongly $\left(K_{\mathrm{a}}>10^{4} \mathrm{M}^{-1}\right)$ in water. Both cages display very strong anion recognition in $\mathrm{I}: \mathrm{I}_{2} \mathrm{O}: \mathrm{d}_{6}$-DMSO: importantly this is not simply unselective binding as might be expected for a system that functions through electrostatics alone. Instead, urea-based cage $4^{6+}$ shows a strong selectivity preference for $\mathrm{SO}_{4}{ }^{2-}$ over $\mathrm{HPO}_{4}{ }^{2-}$, while isophthalamide cage $3^{6+}$ displays cooperative and strong binding of two $\mathrm{HPO}_{4}{ }^{2-}$ anions in preference to $\mathrm{SO}_{4}{ }^{2-}$. High level computational studies are consistent with favourable host-guest interactions between the cages and anions in the highly competitive solvents used in the binding studies. Interestingly, these suggest that amide $\mathrm{N}-\mathrm{H}$ donors present in the cages seem to contribute relatively little to anion binding. Instead binding strength appears to be dictated by the ability of the cages to adopt conformations that place the cationic pyridinium rings close to the anion, as well as interactions between the anions. This suggests that even stronger and more selective binding may be achievable if cages can be synthesised with appropriate binding groups located on or close to the pyridinium rings. The investigation of these types of cages, including more soluble derivatives, are intriguing targets for future study.

\section{EXPERIMENTAL SECTION}

Computational Methodology. Polarisable force fields OPLS-AA and CL\&Pol - were used in molecular dynamics simulations. ${ }^{61}$ Water was described using the SWM4-NDP model.62 For hydrazine linkages force field parameters were taken from LigParGen.63 All simulations were performed with OpenMM. $\mathrm{NpT}$ equilibration simulations at $300 \mathrm{~K}$ and I bar were performed to generate correct atomic velocities, with I ns simulations sufficient for molecular densities to converge to $1.1 \mathrm{~g} / \mathrm{cm}^{3}$. Simulated annealing was performed to generate realistic initial configurations, with 5 cycles of temperature fluctuation between $500 \mathrm{~K}$ and $10 \mathrm{~K}$, with each annealing cycle lasting for I ns. The final cooling step was performed over $2.5 \mathrm{~ns}$. For more detail on the simulation protocol see the Supplementary Information. After annealing, NpT simulations were performed for 100 ps to re-generate atomic velocities corresponding to an overall temperature of $300 \mathrm{~K}$. $10 \mathrm{~ns}$ NVT production simulations were then performed at $300 \mathrm{~K}$ to locate energetically favourable structures of each cage with associated anions of interest, with the minimum energy configurations across the simulation used in subsequent quantum chemical calculations. To extract geometries for further analysis, potential energies were studied every 10 ps to match the frequency of the frames in the trajectory. The frames showing the four or five lowest potential energies across the 10 ns NVT simulation were extracted. A I:I mixture of water and DMSO was used as the solvent in all simulations.

Intermolecular interactions $\left(\Delta \mathrm{E}_{\mathrm{INT}}\right)$ between the cages and anions were calculated using $M 062 X / 6-3 I+G(d, p)$ on the geometries extracted from simulated annealing. The universal solvation model (SMD) with water as solvent was applied to account for solvation effects. $\Delta \mathrm{E}_{\mathrm{INT}}$ was averaged over the extracted geometries and re-calculated to per anion in the system using the following formula:

$$
\Delta E_{I N T}=\left(\frac{E_{\text {system }}^{S M D}-E_{\text {cage }}^{S M D}-\sum_{i}^{n} E_{\text {anion }, i}^{S M D}}{N}\right)
$$

where $n$ is the number of anions modelled in the system and $N$ is the number of extracted geometries. All interaction energies are given in Table S9.

Accession Codes. CCDC 2123004-2123006 contain the supplementary crystallographic data for this paper. These data can be obtained free of charge via www.ccdc.cam.ac.uk/data_request/cif.

\section{ACKNOWLEDGEMENTS}

We thank the Australian Government for funding (RTP Scholarship to EMF). MLC acknowledges an ARC Laureate Fellowship (FLI70I0004I). The authors gratefully acknowledge a generous allocation of computer resources through the Monash eResearch Centre and the National Computational Infrastructure. TGM acknowledges the Australian Government through the International PhD Scholarship. Parts of this research was carried out at the Australian Synchrotron (MX2 beamline). ${ }^{64}$ 


\section{REFERENCES}

I. Kubik, S., Anion recognition in water. Chem. Soc. Rev. 20 I0, 39 (10), 3648-3663.

2. Langton, M. J.; Serpell, C. J.; Beer, P. D., Anion Recognition in Water: Recent Advances from a Supramolecular and Macromolecular Perspective. Angew. Chem. Int. Ed. 20 I6, 55 (6), I9741987.

3. Shannon, R. D., Revised effective ionic radii and systematic studies of interatomic distances in halides and chalcogenides. Acta Cryst A, 1976, 32 (5), 75।-767.

4. Sommer, F.; Kubik, S., Anion binding of a neutral bis(cyclopeptide) in water-methanol mixtures containing up to $95 \%$ water. Org. Biomol. Chem. 20 I4, I 2 (44), 885I-8860.

5. Schiessl, P.; Schmidtchen, F. P., Binding of Phosphates to Abiotic Hosts in Water. J. Org. Chem. I 994, 59 (3), 509-5I I.

6. Langton, M. J.; Robinson, S. W.; Marques, I.; Félix, V.; Beer, P. D., Halogen bonding in water results in enhanced anion recognition in acyclic and rotaxane hosts. Nat. Chem. 20I4, 6, 1039.

7. Kubik, S.; Kirchner, R.; Nolting, D.; Seidel, J., A Molecular Oyster: A Neutral Anion Receptor Containing Two Cyclopeptide Subunits with a Remarkable Sulfate Affinity in Aqueous Solution. J. Am. Chem. Soc. 2002, 124 (43), I2752-I 2760.

8. Custelcean, R.; Williams, N. J.; Seipp, C. A., Aqueous Sulfate Separation by Crystallization of Sulfate-Water Clusters. Angew. Chem., Int. Ed. 201 5, 54 (36), I0525-10529.

9. Schmidtchen, F. P., Inclusion of Anions in Macrotricyclic Quaternary Ammonium Salts. Angew. Chem., Int. Ed. I977, 16 (I0), 720721 .

10. Lee, S.; Chen, C.-H.; Flood, A. H., A pentagonal cyanostar macrocycle with cyanostilbene $\mathrm{CH}$ donors binds anions and forms dialkylphosphate [3] rotaxanes. Nat. Chem. 2013, 5 (8), 704-7I0.

I I. Langton, M. J.; Robinson, S. W.; Marques, I.; Felix, V.; Beer, P. D., Halogen bonding in water results in enhanced anion recognition in acyclic and rotaxane hosts. Nat. Chem. 20 I 4, 6 (I2), 1039-I043.

12. Prohens, R.; Martorell, G.; Ballester, P.; Costa, A., A squaramide fluorescent ensemble for monitoring sulfate in water. Chem. Commun. 200I, (I6), I456-I457.

I3. Zhou, H.; Zhao, Y.; Gao, G.; Li, S.; Lan, J.; You, J., Highly Selective Fluorescent Recognition of Sulfate in Water by Two Rigid Tetrakisimidazolium Macrocycles with Peripheral Chains. J. Am. Chem. Soc. 20 I3, I 35 (40), |4908-|49II.

I4. Qin, L.; Wright, J. R.; Lane, J. D. E.; Berry, S. N.; Elmes, R. B. P.; Jolliffe, K. A., Receptors for sulfate that function across a wide $\mathrm{pH}$ range in mixed aqueous-DMSO media. Chem. Commun. 2019, 55 (82), $12312-12315$.

I5. Rowan, S. J.; Cantrill, S. J.; Cousins, G. R. L.; Sanders, J. K. M.; Stoddart, J. F., Dynamic Covalent Chemistry. Angew. Chem. Int. Ed. 2002, 4 I (6), 898-952.

16. Belowich, M. E.; Stoddart, J. F., Dynamic imine chemistry. Chem. Soc. Rev. 2012, 4 I (6), 2003-2024.

17. Liu, X.; Liu, Y.; Li, G.; Warmuth, R., One-Pot, I8Component Synthesis of an Octahedral Nanocontainer Molecule. Angew. Chem., Int. Ed. 2006, 45 (6), 901-904.

18. Xu, D.; Warmuth, R., Edge-Directed Dynamic Covalent Synthesis of a Chiral Nanocube. J. Am. Chem. Soc. 2008, 130 (24), 75207521 .

19. Wang, L.; Wang, G.-T.; Zhao, X.; Jiang, X.-K.; Li, Z.-T., Hydrogen Bonding-Directed Quantitative Self-Assembly of Cyclotriveratrylene Capsules and Their Encapsulation of C60 and C70. J. Org. Chem. 20I I, 76 (9), 353 I-3535.

20. Tozawa, T.; Jones, J. T. A.; Swamy, S. I.; Jiang, S.; Adams, D. J.; Shakespeare, S.; Clowes, R.; Bradshaw, D.; Hasell, T.; Chong, S. Y.; Tang, C.; Thompson, S.; Parker, J.; Trewin, A.; Bacsa, J.; Slawin, A. M. Z.; Steiner, A.; Cooper, A. I., Porous organic cages. Nat. Mater. 2009, 8 (I2), 973-978

21. Mastalerz, M.; Schneider, M. W.; Oppel, I. M.; Presly, O., A Salicylbisimine Cage Compound with High Surface Area and Selective $\mathrm{CO}_{2} / \mathrm{CH}_{4}$ Adsorption. Angew. Chem. Int. Ed. 20 I I, 50 (5), I046-I05I.

22. Jiang, S.; Jones, J. T. A.; Hasell, T.; Blythe, C. E.; Adams, D. J.; Trewin, A.; Cooper, A. I., Porous organic molecular solids by dynamic covalent scrambling. Nat. Commun. 20 I I, 2 (I), 207.
23. Mal, P.; Schultz, D.; Beyeh, K.; Rissanen, K.; Nitschke, J. R., An Unlockable-Relockable Iron Cage by Subcomponent Self-Assembly. Angew. Chem. Int. Ed. 2008, 47 (43), 8297-830I.

24. Chichak, K. S.; Cantrill, S. J.; Pease, A. R.; Chiu, S.-H.; Cave, G. W. V.; Atwood, J. L.; Stoddart, J. F., Molecular Borromean Rings. Science 2004, 304 (5675), I308-I 3 | 2

25. Pentecost, C. D.; Chichak, K. S.; Peters, A. J.; Cave, G. W. V.; Cantrill, S. J.; Stoddart, J. F., A Molecular Solomon Link. Angew. Chem. Int. Ed. 2007, 46 (I-2), $218-222$.

26. Leigh, D. A.; Lusby, P. J.; Teat, S. J.; Wilson, A. J.; Wong, J. K. Y., Benzylic Imine Catenates: Readily Accessible Octahedral Analogues of the Sauvage Catenates. Angew. Chem. Int. Ed. 200I, 40 (8), I538-I543.

27. Cantrill, S. J.; Rowan, S. J.; Stoddart, J. F., Rotaxane Formation under Thermodynamic Control. Org. Lett. I 999, I (9), I3631366.

28. Glink, P. T.; Oliva, A. I.; Stoddart, J. F.; White, A. J. P.; Williams, D. J., Template-Directed Synthesis of a [2]Rotaxane by the Clipping under Thermodynamic Control of a Crown Ether Like Macrocycle Around a Dialkylammonium Ion. Angew. Chem. Int. Ed. 2001, 40 (10), 1870-1875.

29. Belowich, M. E.; Valente, C.; Stoddart, J. F., TemplateDirected Syntheses of Rigid Oligorotaxanes under Thermodynamic Control. Angew. Chem. Int. Ed. 20 I 0, 49 (40), 7208-72I 2.

30. Wu, Y.-W.; Tung, S.-T.; Lai, C.-C.; Liu, Y.-H.; Peng, S.-M.; Chiu, S.-H., Cyclic [2]Catenane Dimers, Trimers, and Tetramers. Angew. Chem. Int. Ed. 2015, 54 (40), II745-II749.

3I. Uribe-Romo, F. J.; Hunt, J. R.; Furukawa, H.; Klöck, C.; O'Keeffe, M.; Yaghi, O. M., A Crystalline Imine-Linked 3-D Porous Covalent Organic Framework. J. Am. Chem. Soc. 2009, I3 I (I3), 45704571

32. Nguyen, H. L.; Gropp, C.; Ma, Y.; Zhu, C.; Yaghi, O. M., 3D Covalent Organic Frameworks Selectively Crystallized through Conformational Design. J. Am. Chem. Soc. 2020, 142 (48), 20335-20339.

33. Givelet, C.; Sun, J.; Xu, D.; Emge, T. J.; Dhokte, A.; Warmuth, R., Templated dynamic cryptophane formation in water. Chem. Commun. 20 I I, 47 (I5), 45II-45I3.

34. Lin, Z.; Sun, J.; Efremovska, B.; Warmuth, R., Assembly of Water-Soluble, Dynamic, Covalent Container Molecules and Their Application in the Room-Temperature Stabilization of Protoadamantene. Chem. Eur. J. 2012, I8 (40), I2864-I2872.

35. Lei, Y.; Chen, Q.; Liu, P.; Wang, L.; Wang, H.; Li, B.; Lu, X.; Chen, Z.; Pan, Y.; Huang, F.; Li, H., Molecular Cages Self-Assembled by Imine Condensation in Water. Angew. Chem. Int. Ed. 202 I, 60 (9), 4705-47II.

36. Chen, Y.; Wu, G.; Chen, B.; Qu, H.; Jiao, T.; Li, Y.; Ge, C.; Zhang, C.; Liang, L.; Zeng, X.; Cao, X.; Wang, Q.; Li, H., Selfassembly of a purely covalent cage with homochirality via imine formation in water. Angew. Chem. Int. Ed. 202 I, 60 (34), I88I5-I8820.

37. Jiao, T.; Wu, G.; Zhang, Y.; Shen, L.; Lei, Y.; Wang, C.-Y.; Fahrenbach, A. C.; Li, H., Self-Assembly in Water with N-Substituted Imines. Angew. Chem., Int. Ed. 2020, 59 (42), I8350-I8367.

38. Li, H.; Zhang, H.; Lammer, A. D.; Wang, M.; Li, X.; Lynch, V. M.; Sessler, J. L., Quantitative self-assembly of a purely organic threedimensional catenane in water. Nat. Chem. 2015, 7 (12), I003-1008.

39. Wang, C.-Y.; Wu, G.; Jiao, T.; Shen, L.; Ma, G.; Pan, Y.; Li, $\mathrm{H}$., Precursor control over the self-assembly of [2]catenanes via hydrazone condensation in water. Chem. Commun. 20 I 8, 54 (40), 5I 065109.

40. Chen, Q.; Chen, L.; Wang, C.-Y.; Jiao, T.; Pan, Y.; Li, H., Ultramacrocyclization via selective catenation in water. Chem. Commun. 2019, 55 (87), I3108-13। I।.

4I. Wu, G.; Wang, C.-Y.; Jiao, T.; Zhu, H.; Huang, F.; Li, H., Controllable Self-Assembly of Macrocycles in Water for Isolating Aromatic Hydrocarbon Isomers. J. Am. Chem. Soc. 2018, 140 (I8), 5955-596I.

42. Blanco-Gómez, A.; Fernández-Blanco, Á.; Blanco, V.; Rodríguez, J.; Peinador, C.; García, M. D., Thinking Outside the "Blue Box": Induced Fit within a Unique Self-Assembled Polycationic Cyclophane. J. Am. Chem. Soc. 20 I9, I 4 I (9), 3959-3964.

43. Blanco-Gómez, A.; Neira, I.; Barriada, J. L.; Melle-Franco, M.; Peinador, C.; García, M. D., Thinking outside the "Blue Box": from molecular to supramolecular $\mathrm{pH}$-responsiveness. Chem. Sci. 2019, 10 (46), 10680-10686. 
44. Cougnon, F. B. L.; Caprice, K.; Pupier, M.; Bauzá, A.; Frontera, A., A Strategy to Synthesize Molecular Knots and Links Using the Hydrophobic Effect. J. Am. Chem. Soc. 20 I 8, I 40 (39), I2442- 12450.

45. Zheng, X.; Zhang, Y.; Wu, G.; Liu, J.-R.; Cao, N.; Wang, L.; Wang, Y.; Li, X.; Hong, X.; Yang, C.; Li, H., Temperaturedependent self-assembly of a purely organic cage in water. Chem. Commun. 2018, 54 (25), 3138-3।4I.

46. Wang, H.; Fang, S.; Wu, G.; Lei, Y.; Chen, Q.; Wang, H.; Wu, Y.; Lin, C.; Hong, X.; Kim, S. K.; Sessler, J. L.; Li, H., Constraining Homo- and Heteroanion Dimers in Ultraclose Proximity within a SelfAssembled Hexacationic Cage. J. Am. Chem. Soc. 2020, 142 (47), 20I8220190.

47. Xu, Y.-Y.; Liu, H.-K.; Wang, Z.-K.; Song, B.; Zhang, D.-W.; Wang, H.; Li, Z.; Li, X.; Li, Z.-T., Olive-Shaped Organic Cages: Synthesis and Remarkable Promotion of Hydrazone Condensation through Encapsulation in Water. J. Org. Chem. 202 I, 86 (5), 3943-395I.

48. Yang, M.; Qiu, F.; M. El-Sayed, E.-S.; Wang, W.; Du, S.; Su, K.; Yuan, D., Water-stable hydrazone-linked porous organic cages. Chem. Sci. 202 I, I 2 (40), I 3307-133 I5.

49. Hussein, W. M.; Vella, P.; Islam, N. U.; Ollis, D. L.; Schenk, G.; McGeary, R. P., 3-Mercapto-I, 2, 4-triazoles and $\mathrm{N}$-acylated thiosemicarbazides as metallo- $\beta$-lactamase inhibitors. Bioorg. Med. Chem. Let. 2012, 22 (I), 380-386.

50. Li, Z.; Zhu, W.; Yu, J.; Ma, X.; Lu, Z.; Xiao, S., Green Synthetic Method for I, 5-Disubstituted Carbohydrazones. Synth. Commun. 2006, 36 (I8), 2613-2619.

51. We note that when $\mathrm{Li}$ and Sessler attempted to anion exchange the smaller hexacationic cage $\mathbf{2}^{\mathbf{6 +}}$, they observed encapsulation of one halide anion, i.e. isolation of a species containing one $\mathrm{Cl}^{-}$and five $\mathrm{PF}_{6}{ }^{-}$anions, $\mathbf{C l} \subset \mathbf{2} \cdot\left(\mathbf{P F}_{6}\right)_{5}$ (Ref. 46). In our case, we do not observe this.

52. Hoffmann, R.; Schleyer, P. v. R.; Schaefer III, H. F., Predicting Molecules-More Realism, Please! Angew. Chem., Int. Ed. 2008, 47 (38), 7164-7I67.

53. With the urea cage $\mathbf{3}^{6+}$, the pyridinium peaks showed large movements while the imine peak showed only small movements, and so we monitored the movement of the pyridinium peaks. With the isophthalimide cage $\mathbf{4}^{6+}$, the imine peaks showed the largest movement and so these were used to determine association constants. Hydrazone $\mathrm{N}-\mathrm{H}$ peaks were not observed due to $\mathrm{H} / \mathrm{D}$ exchange for both cages. Further information is provided in the Supporting Information.

54. Bindfit, accessed at supramolecular.org.

55. We note that quantifying $\mathrm{HPO}_{4}{ }^{2-}$ anion binding may be complicated by possible antielectrostatic hydrogen bonding interactions between the anions, however we think in the cases described herein, any interactions are likely to negligible due to both the $2^{-}$charge on the anion and the very competitive solvents used.

56. Thordarson, P., Determining association constants from titration experiments in supramolecular chemistry. Chem. Soc. Rev. 201 I, 40 (3), I305-1323.

57. Caballero and coworkers showed the formation of a $\mathrm{H}_{2} \mathrm{PO}_{4}^{-}$ templated polymer by comparing the diffusion coefficient of the monomer without anions and in the presence of anions. With a decrease of the diffusion coefficient implying the formation of a larger species in solution. Zapata, F.; Gonzalez, L.; Caballero, A.; Bastida, D.; Molina, P., Interlocked Supramolecular Polymers Created by Combination of Halogen and Hydrogen-Bonding Interactions through Anion-Template Self-Assembly. J. Am. Them. Soc. 20 I 8, 140 (6), 204I2045.

58. He, Q.; Tu, P.; Sessler, J. L., Supramolecular Chemistry of Anionic Dimers, Trimers, Tetramers, and Clusters. Chem 20 I 8, 4 (I), 46-93.

59. Rajbanshi, A.; Wan, S.; Custelcean, R., Dihydrogen Phosphate Clusters: Trapping $\mathrm{H}_{2} \mathrm{PO}_{4}-$ Tetramers and Hexamers in Urea-Functionalized Molecular Crystals. Cryst. Growth Des. 20 I 3, I 3 (5), 2233-2237.

60. Zhao, W.; Flood, A. H.; White, N. G., Recognition and applications of anion-anion dimers based on anti-electrostatic hydrogen bonds (AEHBs). Chem. Soc. Rev. 2020, 49 (22), 7893-7906.

61. Canongia Lopes, J. N.; Pádua, A. A. H., CL\&P: A generic and systematic force field for ionic liquids modeling. Theor. Chem. Acc. 20 I 2, I3I (3), II29.
62. Lamoureux, G.; Harder, E.; Vorobyov, I. V.; Roux, B.; MacKerell, A. D., A polarizable model of water for molecular dynamics simulations of biomolecules. Chem. Phys. Lett. 2006, 4 I 8 (I), 245-249.

63. Dodda, L. S.; Cabeza de Vaca, I.; Tirado-Rives, J.; Jorgensen, W. L., LigParGen web server: an automatic OPLS-AA parameter generator for organic ligands. Nucleic Acids Res. 20 I 7, 45 (WI), W33 IW336.

64. Aragão, D.; Aishima, J.; Cherukuvada, H.; Clarken, R.; Clift, M.; Cowieson, N. P.; Ericsson, D. J.; Gee, C. L.; Macedo, S.; Mudie, N., MX2: a high-flux undulator microfocus beamline serving both the chemical and macromolecular crystallography communities at the Australian Synchrotron. J. Synchrotron Radiat. 20 I 8, 25 (3), 885-89I. 